\title{
Breve síntesis sobre el armamento en Egipto durante las dinastías XIX y XX
}

\section{Brief synthesis about the armament in Egypt durin XIXth and $X X$ th dynasties}

\author{
JaVier MARTínez BABÓN
}

Escuela de Egiptología de la Fundación Arqueológica Clos de Barcelona

\begin{abstract}
RESUMEN
ABSTRACT

Los ejércitos de Seti y de Ramses II que lucharon contra los hititas estaban en posesión de la mayoría de las armas más modernas de su época. Las tropas egipcias dependían de los carros y de la infantería que esencialmente luchaba con hachas, espadas cortas, espadas de hoz, jabalinas, mazas, venablos, hondas y se defendían con escudos.

El uso de cascos, cotas de placas de bronce se extendió con rapidez y los mercenarios shardana introdujeron las espadas largas.

Con la crisis política a finales de la dinastía XIX, y la pérdida de territorios a

inicios de la dinastía del $X X$, el ejército perdió también parte de sus recursos y los artesanos asiáticos especializados en la metalurgia.

PALABRAS CLAVE: Ejército, armas, Imperio Nuevo Egipcio, The army of Seti I and Ramses II, which fought against the hittites, possessed the most modem weapons of that era. The Egyptian troops depended upon chariots and infantry which essentially fought with axes, short swords, sickle swords, spears, javelins, lances, self and composite bows and who defended themselves with shields.

The use of helmets and coats of mail became more and more widespread and the shardana mercenaries introduced long swords.

With the political crisis at the end of the $X I X$ th. Dynasty and the loss of territory at the beginning of the XXth. Dynasty, the army lost its arms resources, which come from Asian towns specialized in metallurgy.

KEYWORDS:

Army, arms, Egyptian New Kingdom, matellurgy.
\end{abstract}


Estas líneas han sido diseñadas como un complemento histórico a un artículo publicado en esta revista sobre armas de la dinastía XVIII'.

Las dinastías XIX y XX forman, junto a la XVIII, el período egipcio conocido como Imperio Nuevo (ca. 1552-1070 a. C.). En esa época el país del Nilo era una de las potencias más importantes del Próximo Oriente, asiático gracias a un ejército profesionalizado que fue dotándose del armamento más moderno de aquellos tiempos.

Los acontecimientos más relevantes en el ámbito militar que tuvieron lugar a lo largo de ambas dinastías fueron: las campañas de reconquista de Seti I contra sirios e hititas ${ }^{2}$; las acciones de Ramsés II, entre las que destacan la célebre batalla de Kadesch, la expedición a Transjordania y el asalto a la plaza fuerte siria de Dappur $^{3}$; las operaciones, dentro y fuera de Egipto, protagonizadas por los hombres de Merenptah ${ }^{4}$ y la angustiosa defensa de los límites territoriales contra invasores libios y Pueblos del Mar acaecida bajo Ramsés III ${ }^{5}$. La fortuna ha permitido que muchos relieves sobre estos enfrentamientos militares se hayan conservado, constituyendo, obviamente, una fuente magnífica para el estudio militar y armamentístico de la época en cuestión ${ }^{6}$.

1 J. MARTínez BABÓN: Breve síntesis sobre la introducción de nuevo armamento en Egipto durante la

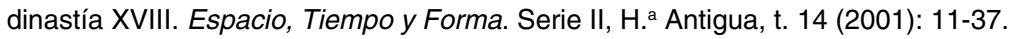

2 Las acciones militares de Seti I han sido tratadas por diferentes autores, entre los cuales cabe destacar: R. O. FAULKNER (The Wars of Sethos I. JEA 33 (1947): 34-39); A. SPALINGER (The Northern Wars of Seti I: An Integrative Study. JARCE 16 (1979): 29-47) y J. W. MuRnANE (The Road to Kadesh. A Historical Interpretation of the Battle Reliefs of King Sety I at Karnak. SAOC 42, 1985/90).

3 Buenas síntesis sobre las operaciones militares en tiempos de Ramsés II se encuentran en K. A KITCHEN (Some New Light on the Asiatic Wars of Ramesses II. JEA 50 (1964): 47-70; Pharaoh Triumphant. The Life and Times of Ramesses II. Warminster/Mississauga, 1982) y C. VANDERSLEYEN (L'Égypte et la vallée du Nil. De la fin de l'Ancien Empire à la fin du Nouvel Empire. París, 1995: 521-532). Los textos sobre la batalla de Kadesch y la interpretación histórica de los mismos han sido tratados por numerosos investigadores, siendo algunos de los más representativos: J. H. BREASTED (The Battle of Kadesh. Chicago, 1903); R. O. FAULKNER (The Battle of Qadesh, MDAIK 16 (1958): 93-111); A. GARDINER (The Kadesh Inscriptions of Ramesses II. Oxford, 1960); H. GoEdickE (ed.) (Perspectives on the Battle of Kadesh. Baltimore, 1985) y W. MAYER/R. MAYER-OPIFICIUS (Die Schlacht bei Qadés. Der Versucht einer neuen Rekonstruktion. UF 26 (1994): 321-368). Sobre la operación de Ramsés II en tierras transjordanas resulta muy interesante el artículo de P. W. HAIDER (Zum Moab-Feldzug Ramses' II. SAK 14 (1987): 107-123). En lo que refiere a las operaciones militares de Ramsés II en Siria, menos conocidas pero muy importantes, se puede consultar el artículo de S. MORSCHAUSER (On the «Plunder of Dapur». BES 7 (1985/86): 15-28).

4 Sobre las acciones bélicas asiáticas en tiempos de este faraón cabe destacar el trabajo de F.J. YuRKo (Merenptah's Canaanite Campaign. JARCE 23 (1986): 189-215). La dispersa y fraccionada información sobre las operaciones acaecidas en tierra egipcia contra libios y Pueblos del Mar no ha resultado atractiva para los investigadores. Aun así, podemos subrayar el trabajo de C. VANDERSLEYEN (op. cit.: 561-571).

5 Algunos de los profesionales que han tratado estos eventos son R. STADELMANN (Die Abwehr der Seevölker unter Ramses III. Saeculum 19 (1968): 156-171); L. H. LESKo (The Wars of Ramses III. Serapis 6 (1980): 83-86) y P. GRANDET (Ramsès III. Histoire d'un règne. París, 1993: 161-216).

6 Estos relieves aparecen publicados en distintas obras y colecciones. Una completa y moderna recopilación es la obra de S. C. HEINZ, Die Feldzugsdarstellungen des Neuen Reiches. Eine Bildanalyse. Viena, 2001. El conjunto de fuentes sobre material bélico del Imperio Nuevo presenta una curiosa paradoja; la dinastía XVIII ha legado numerosas armas y pocas representaciones bélicas en tanto que las dinastías XIX y XX han dejado pocas armas y abundante iconografía de guerra. 


\section{EL EJÉRCITO DE LAS DINASTÍAS XIX Y XX}

Las Fuerzas Armadas de esta época eran una compleja maquinaria bélica dividida, a efectos administrativos, en dos grandes armas: infantería y carros de gue$\mathrm{rra}^{7}$. La unidad básica de encuadre para la infantería era una compañía de 250 soldados que podía dividirse en cinco secciones de 50 soldados. 20 compañías, que sumaban unos 5000 hombres, constituían una brigada de infantería, la cual, junto a un escuadrón de 50 carros, formaba una división de combate ${ }^{8}$. Por su parte, los escuadrones de carros de guerra estaban formados por secciones de 10 vehículos ${ }^{9}$. Cada unidad de combate tenía su propio nombre y estandarte ${ }^{10}$. A partir del gobierno de Ramsés II hay constancia de la existencia de cuatro divisiones en activo que portaban los nombres de las divinidades principales de las ciudades que las albergaban: Amun de Tebas, Ptah de Menfis, Re de Heliópolis y Sutej de PiRamsés. El hecho de que textos sobre acciones militares comandadas por Seti I citen explícitamente tres de estas divisiones encabezadas por el término "primera" permite la suposición de que había una segunda de cada una de ellas en la reserva ${ }^{11}$.

El comandante en jefe de todos los ejércitos de Egipto era el rey, quien podía delegar esta función a su príncipe heredero. Por debajo de los miembros de la Casa Real había una amplia jerarquía cuyos tres rangos más representativos eran los de general, comandante de tropa y portaestandarte ${ }^{12}$. La alta oficialidad provenía de personajes cercanos a la familia del rey y podía incluir, contrariamente a épocas anteriores, a hombres de ascendencia asiática ${ }^{13}$. Los soldados procedían de las familias egipcias y nubias que residían en las colonias militares ${ }^{14}$. A

7 Durante la primera fase de la dinastía XVIII existía solamente una administración y jerarquía para el ejército. La división en dos ramas se produjo en el período que engloba los gobiernos de Amenhotep III y Ajenatón, según demuestra la inclusión de nuevos rangos (R. O. FAULKNER, Egyptian Military Organization. JEA 39 (1953): 32-47; A. R. Schulman, Military Rank, Title and Organization in the Egyptian New Kingdom. MÄS 6 (1964): 14-15; A. M. GNIRS, Militär und Gesellschaft: Ein Beitrag zur Sozialgeschichte des Neuen Reiches. Heidelberg, 1996: 17-18).

8 Esta información se obtiene de una inscripción, datada en el año 3 de Ramsés IV, que se encuentra en el Uadi Hammamat (leer, por ejemplo, en A. R. Schulman, op. cit::124).

9 A. R. Schulman, The Egyptian Chariotry: A Reexamination. JARCE 2 (1963): 90.

10 Sobre los distintos estandartes se puede consultar el artículo de R. O. FAULKNER, Egyptian Military Standards. JEA 27 (1941): 12-18.

11 En la Segunda Estela de Beit-Schean, que informa sobre una operación militar protagonizada por tropas de Seti I contra ciudades palestinas, encontramos los siguientes términos: "Primera división de Amun, Poderoso de Arcos»... «Primera división de Re, Abundante en Valor» ... «Primera división de Sutej, Poderoso de Arcos» (KRI, I, 12: 10). El término «primera», como ya apuntó R. O. FAULKNER en su momento (1947: 37), tal vez implicara la existencia de una segunda división en reserva.

12 Sobre rangos y títulos en el ejército neoimperial resultan muy útiles las obras de A. R. ScHULMAN (1964) y P. M. Chevereau, Prospographie des cadres militaires égyptiens du Nouvel Empire. París, 1994.

${ }_{13}$ En tiempos de Seti I y Ramsés II, por ejemplo, tenemos documentada la presencia del general, de origen hurrita, Urhiya, cuyos méritos le permitieron obtener una buena posición social (K. A. KITCHEN, 1982: 139-140).

14 Aun cuando no existe demasiada información sobre las colonias militares, podemos destacar la alusión a las mismas que efectúa Ramsés II en las agrias palabras, según el Poema de Pentaur, que dedica a sus hombres por la cobardía demostrada ante el ataque por sorpresa que efectuaron los carros hi- 
partir de la época de Amenhotep III/Ajenatón, en la última fase de la dinastía $\mathrm{XVIII}$, comenzó una utilización de numerosos mercenarios de distintas procedencias geográficas que aumentaría considerablemente durante las dinastías XIX y $X X$. Una evidencia del número de extranjeros se encuentra en la siguiente relación de soldados que formaban parte de una unidad de 5000 infantes citada en documentos datados a finales de la dinastía XIX: 1900 egipcios, 520 schardana, 1600 libios kehek, 100 libios mescheuesch y 880 nubios, sin contar la oficialidad ${ }^{15}$. Esta información queda refrendada por la cantidad de soldados extranjeros en las filas egipcias que se puede observar en los relieves del templo funerario de Ramsés III en Medinet Habu (fig.1).

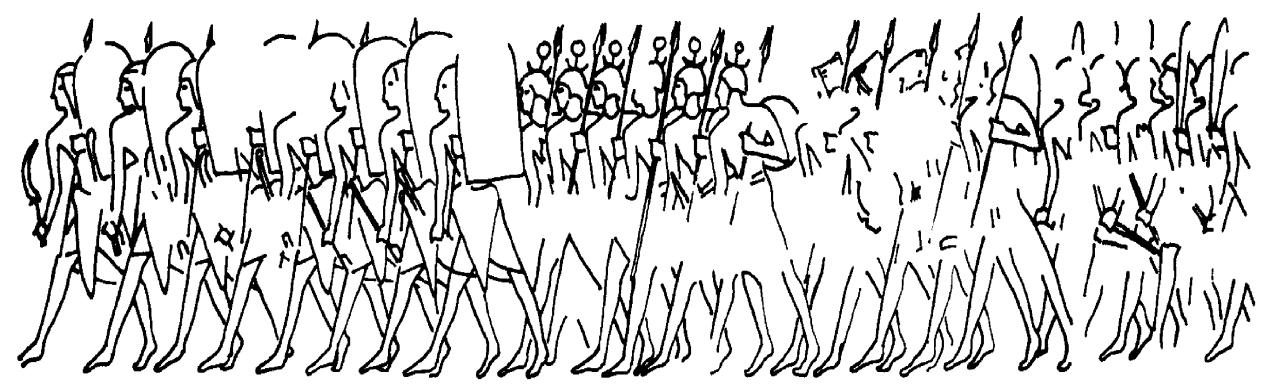

Figura 1. Unidades del ejército egipcio escoltando al rey en una cacería de leones. Relieve cinegético del templo funerario de Ramsés III en Medinet Habu. Dibujo a partir de W. WRESZINSKI, Atlas zur altägyptischen Kulturgeschichte, vol. II, Leipzig 1923-38: lám.115.

De todos los guerreros foráneos que sirvieron a los faraones de esta época, los schardana poseían el armamento más vistoso: espada larga, lanza, escudo redondo, casco con cuernos y, en algunos relieves de Abu Simbel y Medinet Habu, corselete o cota formado por láminas horizontales (fig.2).

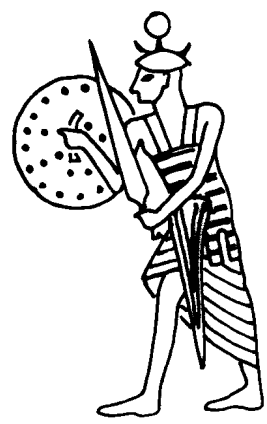

Figura 2. Mercenario schardana de la guardia real de Ramsés II. Relieve bélico del muro oeste de la gran sala del templo mayor de Abu Simbel.

titas: «Ningún Señor ha concedido a su ejército las cosas que yo os he otorgado ante vuestro deseo. Yo he permitido que residiérais en vuestras ciudades* (colonias) sin efectuar servicio militar» (KRI II, 58-59). 15 Papiro Anastasi I, 17-18; Ostracon Gardiner 364, 3-10. 


\section{ANTECEDENTES ARMAMENTÍSTICOS}

A lo largo de la dinastía XVIII las estructuras militares egipcias fueron mejorando el armamento tradicional e incorporando nuevas armas gracias al control sobre importantes centros metalúrgicos ubicados en el Próximo Oriente asiático. A finales del citado período, y aun cuando a nivel de política internacional el país del Nilo perdió protagonismo en beneficio de Hatti ${ }^{16}$, las tropas faraónicas contaban con el siguiente armamento:

- Infantería pesada: Soldados portadores de escudo, protector genital, lanza y hacha. A partir de la época amarniense se extendió el uso de la espada curva en sustitución del hacha, aunque ésta siempre tendría una mayor importancia.

- Infantería ligera: Soldados portadores de arco simple o compuesto y flechas con puntas de bronce palmiformes o romboidales.

- Unidades de carros: Soldados que fueron incorporando la cota y el casco a partir del gobierno de Thutmés III, y que combatían, básicamente, con hacha, arco compuesto, flechas y venablos con punta de bronce.

A estos objetos bélicos cabe añadir puñales y espadas cortas fundidos en una pieza de bronce que habían sido introducidos en Egipto a finales de la época hicsa. Estas armas, de gran efectividad, eran portadas principalmente por oficiales y guerreros que habían sido condecorados con el Oro de la Valentía ${ }^{17}$.

\section{ARMAS E INNOVACIONES TECNOLÓGICAS DURANTE LAS DINASTÍAS XIX Y XX}

Según las fuentes escritas, los relieves y las piezas bélicas que se han conservado, las tropas que combatieron bajo las órdenes de Seti I, Ramsés II, Merenptah o Ramsés III eran profesionales que poseían una amplia panoplia armamentística capaz de rivalizar con los ejércitos más avanzados del Próximo Oriente asiático. En base a lo expuesto, y subrayando la fundamental importancia que tiene el hallazgo de cuadras y dependencias para unidades de carros en la antigua Pi-Ramsés ${ }^{18}$, así como el abundante armamento que fue pintado en una pared de

16 Sobre la situación geopolítica en Siria y las pérdidas territoriales egipcias en esa época leer, por ejemplo, en W. J. MuRNANE (1990: 22ss).

17 El Oro de la Valentía era una condecoración pública consistente en entrega de joyas y armas lujosas a hombres de armas que habían demostrado su valor en el campo de batalla. Se conservan numerosas evidencias de la dinastía XVIII como, por ejemplo, las referencias que aparecen en las biografías de los oficiales Ahmose, hijo de Ebana, y Amenemheb, llamado Mahu.

18 Una buena publicación con fotografías y explicaciones sobre el armamento encontrado en los 3000 m2 excavados es la de E. B. Pusch («Pi-Ramesse-geliebt-von-Amun, Hauptquartier Deiner Streitwagentruppen». Ägypter und Hethiter in der Delta-Residenz der Ramessiden. ZBA 12 (1993): 126-144). 
la tumba de Ramsés III ${ }^{19}$, se pueden destacar las siguientes armas, con sus correspondientes particularidades:

\section{Carros de guerra:}

Vehículos con ruedas de seis radios que aumentaron notablemente su capacidad de combate en relación a épocas anteriores al incrementar el número de armas que portaban. Los relieves muestran carros que tenían hasta tres cajas alargadas para guardar arcos compuestos, flechas y venablos (fig.3).

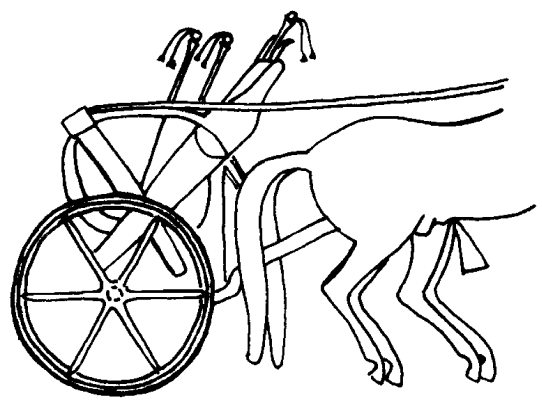

Figura 3. Detalle de un carro de guerra de la dinastía XIX. Relieve bélico de Seti I en la parte exterior del muro norte de la Sala Hipóstila del templo de Karnak.

El papiro ramésida Koller contiene un texto que informa sobre las armas que portaba un carro de guerra ${ }^{20}$. Aunque parte de la narración está deteriorada y algunos de los términos son difíciles de traducir, parece evidente que el armamento básico estaba compuesto por arcos, 80 flechas, venablos, lanzas, espadas y cotas. Este dato coincide con los trabajos arqueológicos en Pi-Ramsés, que han sacado a la luz puñales y espadas cortas fundidos en una pieza de bronce, numerosas puntas de flecha y venablo, así como placas de bronce que formaban parte de cotas o corseletes (leer más abajo).

\section{Armas para el combate cuerpo a cuerpo:}

- Hachas: A pesar de las innovaciones tecnológicas que se produjeron a lo largo del Imperio Nuevo, el hacha continuó siendo un arma importante para los soldados de infantería, según demuestran los relieves (fig. 4-a/b) y las piezas encontradas.

19 Ver, por ejemplo, en J. F. Champolıion, Monuments de l'Egypte et de la Nubie. París, Vol. III, 1845: láms 263-264.

20 Leer traducción a la lengua inglesa, por ejemplo, en R. A. CAminos, Late Egyptian Miscellanies. Londres, 1954: 431. 

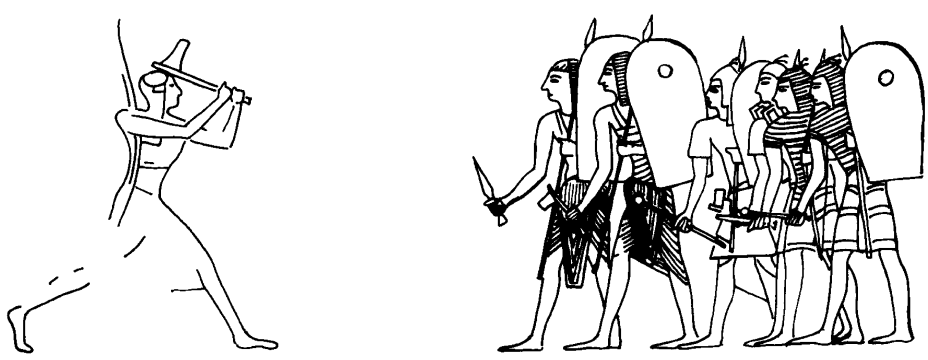

Figura 4. A: Príncipe ramésida con arco y hacha. Relieve bélico de Ramsés Il en el muro norte del patio del templo de Beit el-Walli. B: Soldados egipcios armados con hachas, puñales y mazas. Relieve bélico del templo funerario de Ramsés III en Medinet Habu. Dibujo a partir de J. C. WILKINSON, The Ancient Egyptians. Their Life and Customs, vol. I, Londres 1853 (reed. 1994): 369.

En esta época, las hojas de bronce eran anchas, medían, aproximadamente, entre 10 y $12 \mathrm{~cm}$ de longitud y poseían largos apéndices laterales que facilitaban su sujección al enmangue de madera ${ }^{21}$. En algunos puntos asociados a este período, como el Ramesseum, se han encontrado hojas de hacha de hierro. Sin embargo, hay dudas sobre si son contemporáneas o posteriores ${ }^{22}$. Baste tener en cuenta que de todo el material metálico encontrado en el Mediterráneo Oriental y datable en torno a la crisis del 1200 a. C., únicamente un $3 \%$ es de hierro ${ }^{23}$.

- Espadas curvas: Las espadas curvas fueron armas asociadas a la realeza $y$, por tanto, usadas por el faraón en el campo de batalla ${ }^{24}$ (fig. 5).

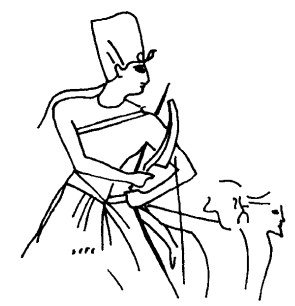

Figura 5. Merenptah con corona azul, arco compuesto y espada curva capturando a dos enemigos asiáticos. Relieve bélico en la parte exterior del muro oeste del patio de la cachette del templo de Karnak.

21 Así lo demuestran las piezas que se han conservado y que pueden ser datadas en esta época. Leer en W. V. DAVIES, Catalogue of Egyptian Antiquities in the British Museum. Tools and Weapons. Axes. Londres, 1987: 46, 48-50.

22 Ibid.: 49. Armas de hierro, como objetos de lujo, están documentadas en fuentes escritas y arqueológicas de finales de la dinastía XVIII.

${ }_{23}$ R. Drews, The End of the Bronze Age. Changes in Warfare and the Catastrophe ca. 1200 B.C. Princeton, 1993: 75. Esta información proviene de un trabajo anterior elaborado por J. WALDBAUM.

24 El papel de la espada curva dentro de la simbología político-religiosa de Egipto se pone de manifiesto con la cantidad de relieves en pilonos y estelas donde son visibles estas armas en manos de reyes y dioses. Información concisa al respecto se encuentra en H. W. MüLLER, Der Waffenfund von Balata-Sichem und die Sichelschwerter. BAW 97 (1987): 139-149. 
Como ya ha sido indicado, determinadas uninades de infantería iban armadas con estas espadas en lugar de las tradicionales hachas (fig.6).

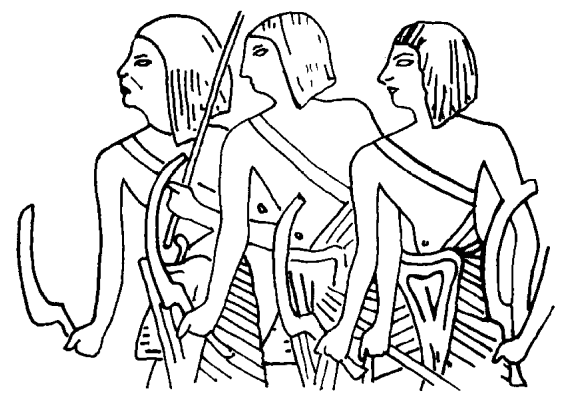

Figura 6. Soldados egipcios armados con espadas curvas. Fragmento de relieve bélico de la dinastía XIX. Hildesheimer Museum, nr. 4571. Dibujo a partir de H. KAYSER, Die ägyptischen Altertümer im Roemer-Pelizaeus Museum in Hildesheim. Hildesheim, 1973: fig. 50.

Se han conservado diversas piezas de este tipo halladas en distintos puntos del Próximo Oriente y datadas en el siglo XIII a. C. ${ }^{25}$. En Egipto, se puede destacar una hermosa empuñadura que muestra los cartuchos de Seti I (fig.7-a),y una espada de $57 \mathrm{~cm}$ de longitud, con hoja y empuñadura fundidas en una pieza de bronce y final romo, que porta los cartuchos de Ramsés II en la empuñadura (fig.7-b). Generalmente, estas armas aparecen muy estilizadas en los relieves y pinturas de esta época. Y ello ha generado confusión en cuanto a su verdadera forma (fig.7-c).
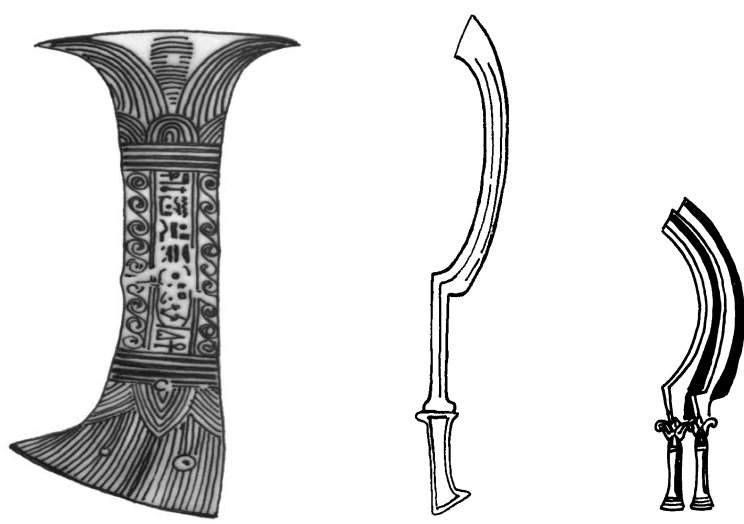

Figura 7. A: Empuñadura de espada curva de bronce negro e incrustaciones de oro y cobre con el nombre de Seti I. Brooklyn Museum, acc. no. 49167. Dibujo a partirde H. W. MüLLER, op. cit.: 153. B: Espada curva de bronce con el nombre de Ramsés II en la empuñadura. Museo del Louvre, E 25689. Dibujo a partir de H. W. MülLER, op. cit.: 152. C: Espadas curvas estilizadas pintadas en la KV 11, tumba de Ramsés III en el Valle de los Reyes. Dibujo a partir de J. F. Champollion, Monuments de l'Égypte et la Nubie. París 1845, vol. III: lám. 264.

25 Ibid.: 152, 158, 163-165. 
- Puñales y espadas cortas: Este tipo de armas, con empuñadura y hoja fundidas en una pieza de bronce, fueron escasas dentro de la dinámica armamentística egipcia anterior a la época en cuestión. Como ya ha sido destacado, eran objetos de lujo destinados a hombres y unidades sobresalientes. Las dependencias militares de Pi-Ramsés han legado a la posteridad algunos puñales de bronce con hoja plana de doble filo unida a una empuñadura que tiene guardamanos corto, parte central vacía para ser cubierta con cachas de madera, hueso o marfil, y pomo abotonado (fig.8-a). Los relieves bélicos presentan, ocasionalmente, soldados armados con estos objetos (fig.8-b) en tanto que la armería pintada en la tumba de Ramsés III muestra unas cuantas espadas cortas, de cuyos pomos penden cordones (fig.8-c), y espadas con extremo romo (fig.8-d).
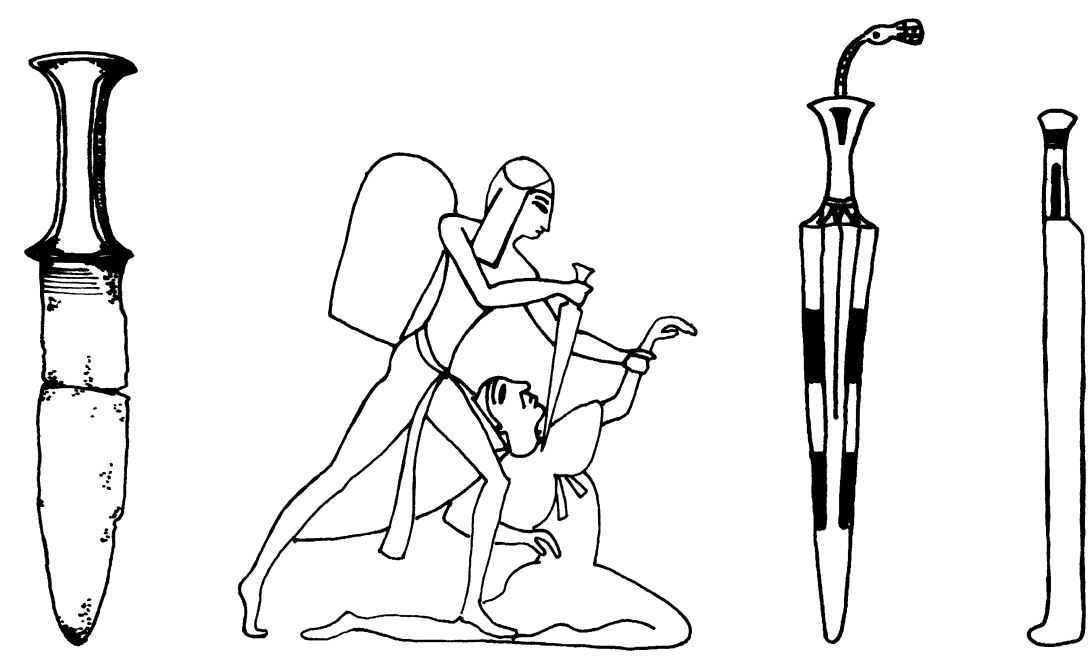

Figura 8. A: Puñal de bronce hallado en un taller de una unidad de carros de guerra de la antigua Pi-Ramsés. Dibujo a partir de la foto en E. B. PusCH, 1993: 134, fig. 132. B: Príncipe egipcio degollando a un enemigo hitita con una espada corta. Relieve sobre la batalla de Kadesch en el muro oeste de la Sala Hipóstila del Ramesseum. Dibujo a partir de J. C. WILKINSON, op. cit.: 359. C: Espada corta pintada en la KV 11. Dibujo a partir de J. F. Champollion, op. cit.: lám. 264. D: Espada, o machete, sin punta afilada. Dibujo a partir de J. F. ChAMPOLlion, op. cit.: lám. 263.

- Bastones y mazas: Los bastones, fácilmente elaborables, siempre tuvieron gran importancia en los ejércitos antiguos. Objetos de este tipo con guardamanos eran utilizados en entrenamientos y exhibiciones castrenses, según evidencian relieves y pinturas hallados en tumbas del Imperio Nuevo ${ }^{26}$. Sin embargo, algunas unidades de combatientes de la dinastía XX portaban una modalidad de bastón, de unos $100 \mathrm{~cm}$ de longitud, que poseía un

${ }^{26}$ Sobre la lucha con bastones resulta muy ilustrativo el enfoque de W. DECKER, Sports and Games of Ancient Egypt. New Haven/Londres, 1992: 82-87. 
guardamanos y un extremo metálico con el que era fácil ocasionar graves heridas a un enemigo poco protegido ${ }^{27}$ (ver en figuras 1 y 4-b). En la tumba de Ramsés III están representados con todo lujo de detalles bastones para la guerra (fig.9).

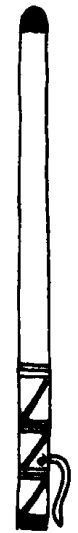

Figura 9. Bastones de combate con protección de manos pintados en la KV 11. Dibujo a partir de J. F. CHAMPOLLION, op. cit.: lám. 264.

Las mazas con cabeza pétrea habían sido armas de uso común en tiempos protohistóricos aunque fueron perdiendo importancia en el campo de batalla durante las primeras dinastías debido a su progresiva sustitución por hachas de hoja metálica ${ }^{28}$. A pesar de ello, las mazas con cabeza piriforme se convertirían en un símbolo del poder faraónico que perviviría a lo largo de los $\operatorname{siglos}^{29}$. Si en representaciones bélicas de la dinastía XIX aparecen ocasionalmente en manos de algunos soldados, en relieves militares de la dinastía XX son frecuentes. Semejante dato permite afirmar que a finales del Imperio Nuevo estos artilugios bélicos fueron utilizados masivamente para la guerra (ver, por ejemplo, en fig. 4-b).

- Lanzas: Los relieves indican que los infantes pesados combatían con una lanza cuya longitud era algo menor a la de sus cuerpos (ver en figuras 1 y 4-b). La gran variedad de puntas de lanza encontrada en diversos lugares de la geografía egipcia crea grandes dificultades a la hora de intentar establecer una tipología. Hasta donde se sabe, la práctica totalidad de hojas de

27 W. WoLF, Die Bewaffnung des Altägyptischen Heeres. Leipzig, 1926: 79. Este egiptólogo aportaba información sobre un bastón del Louvre cuya longitud era de $126 \mathrm{~cm}$ y otro de Berlín que medía $102 \mathrm{~cm}$.

28 Ibid:: 8.

29 Una buena recopilación de escenas de masacre de enemigos en la cual se puede observar la maza con cabeza piriforme en manos del rey, se encuentra en la obra de E. S. HALL, The Pharaoh Smites His Enemies. MÄS 44, 1986. 
lanza de esta época era de bronce, muchas poseían nervatura central y casi todas tenían una prolongación hueca por la cual era introducido un extremo de caña o vara (fig.10).

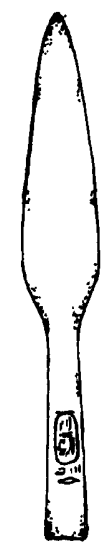

Figura 10. Punta de lanza de bronce con el nombre de Ramsés II. Dibujo a partir de W. Wolf, op. cit.: lám. 6, nr. 8.

\section{Armas arrojadizas:}

- Arcos y flechas: Estas armas tenían gran importancia, tanto para las unidades de carros como para las de infantería ligera. Según los relieves, los arcos compuestos, más potentes que los simples, fueron utilizados cada vez con mayor frecuencia ${ }^{30}$. La arqueología, por su parte, ha brindado arcos simples y arcos compuestos pertenecientes a este período. De los primeros podemos destacar la vara de $155 \mathrm{~cm}$ hallada en la tumba tebana del funcionario Bekenjons y de los segundos cabe mencionar los $105 \mathrm{~cm}$ que se conservan de una pieza con listones de madera y tiras de tendón de buey encontrada en otra tumba tebana ${ }^{31}$. En cuanto a las flechas, se produjeron innovaciones sustanciales, ya que las puntas de bronce fueron modificadas: las antiguas puntas palmiformes y romboidales fueron sustituidas progresivamente por puntas que poseían espolones laterales (fig.11). Al margen de la mejora aerodinámica, esta forma dificultaba la extracción de la punta en el cuerpo de un guerrero herido.

30 Los relieves militares muestran numerosos arcos compuestos, en su esquemática forma triangular, portados por soldados egipcios.

${ }_{31}$ W. Wolf, op. cit: : 80-83, lám. 16, nrs. 1 y 3. También se puede obtener información sobre el arco compuesto en W. McLeod, Composite Bows from the Tomb of Tut'ankhamun. Oxford, 1982: 29, G. 


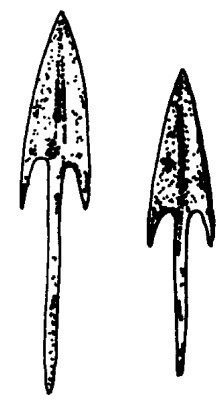

Figura 11. Puntas triangulares de flecha de bronce con largos espolones laterales. Longitudes: 10'5 y 8'5 cm. Museo Egipcio de Berlín, nrs. 17297 y 11502. Dibujo a partir de foto en W. WolF, op. cit.: lám. 8, nrs. 17 y 18.

- Venablos: Estos objetos bélicos eran utilizados básicamente por las unidades de carros y presentaban las siguientes características: longitud aproximada de 125 a $150 \mathrm{~cm}$, punta de bronce, y estabilizadores formados por una bola y dos cordones. Clásicos son los relieves de Seti I y Ramsés II en los que estos faraones se disponen a rematar a un enemigo con un arma de estas características (fig. 12).

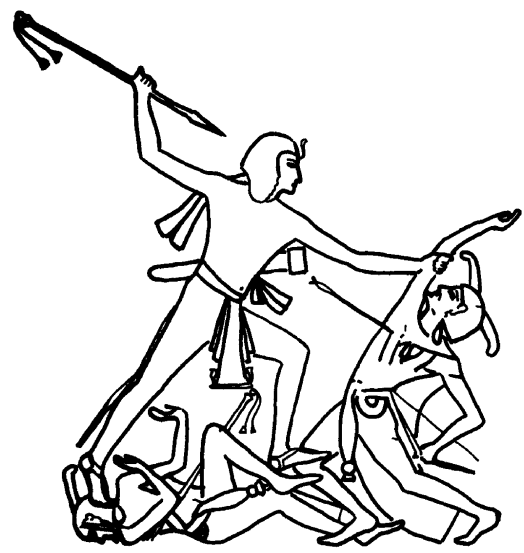

Figura 12. Seti I en ademán de matar a un enemigo Libio con un venablo. Relieve bélico en la parte exterior del muro norte de la Sala Hipóstila del templo de Karnak.

- Hondas: En comparación con otras armas arrojadizas, las hondas fueron objetos poco utilizados por los egipcios a lo largo de su historia. En lo que refiere a las dinastías XIX y XX se han encontrado pocos indicios de su uso. Uno de los más representativos, sin embargo, aparece en el relieve de la gran batalla naval esculpido en el templo funerario de Ramsés III: un hondero se dispone a lanzar su mortífero proyectil desde el mástil de un bajel egipcio (fig. 13) 


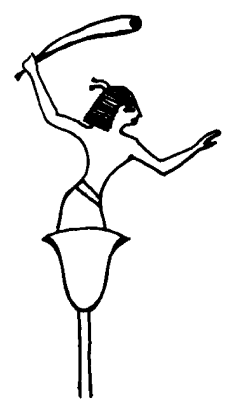

Figura 13. Hondero dispuesto a actuar desde el mástil de una nave de guerra. Relieve bélico del templo funerario de Ramsés III en Medinet Habu. Dibujo a partir de J. G. WILKINSON, op. cit.: 357.

\section{Protecciones corporales:}

- Escudos y protecciones genitales: Los escudos presentaban características similares a los de la última fase de la dinastía XVIII: piezas de madera, de unos $100 \mathrm{~cm}$ de longitud, $70 \mathrm{~cm}$ de anchura y parte superior en forma semicircular. Ocasionalmente poseían un orificio por el que el soldado podía mirar con la cabeza protegida o un emblema de una unidad de combate.

En las excavaciones de Pi-Ramsés han sido encontrados interesantes moldes para el revestimiento metálico de los laterales de escudos, que presentan la forma típica de las protecciones hititas representadas en relieves militares del gobierno de Ramsés II (fig.14). Esta particularidad demuestra que algunos artesanos hititas trabajaron en la capital egipcia al servicio del faraón ${ }^{32}$. Obviamente, debemos suponer que esta colaboración se

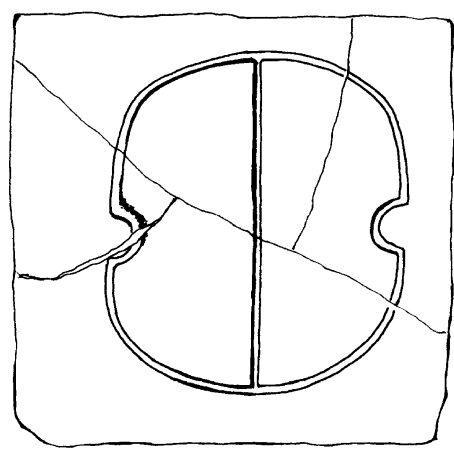

Figura 14. Molde para escudo de origen hitita hallado en la antigua Pi-Ramsés. Dibujo a partir de foto en E. B. PuSCH, 1993: 136, fig. 135.

${ }^{32}$ E. B. Pusch, op. cit:: 142. La cuestión que plantea gira en torno al momento inicial de esta colaboración; lo más lógico es suponer que se produjo a raíz del tratado de paz y amistad. 
produjo a raíz del Tratado de paz y amistad firmado en el año 21 del gobierno de Ramsés II. Las protecciones genitales, que aparecen reiteradamente en escenas militares de esta época, tenían forma triangular (ver en figuras 1, 2 y 6). Nada se sabe sobre el material utilizado sobre su elaboración, aunque cabe suponer que era lino o cuero.

- Cotas y cascos: Estas defensas corporales fueron utilizadas, como ha sido indicado, por los soldados de carros. En Pi-Ramsés se han encontrado restos de cotas en forma de pequeñas placas de bronce con diminutos orificios por los que pasaban los hilos que las unían a una prenda de ropa (fig.15-a). Estas cotas, las cuales ya están documentadas en antiguos textos de Nuzi y cuyas primeras evidencias de su uso en Egipto se encuentran a mediados de la dinastía XVIII ${ }^{33}$, se pueden observar, pintadas de distintos colores, en la tumba de Ramsés III ${ }^{34}$ (fig.15-b). Los relieves de Abu Simbel, sin embargo, presentan un nuevo tipo de protección portado por los mercenarios schardana y por algunos soldados egipcios de la guardia real, cuya característica esencial viene marcada por una serie de placas horizontales que cubrían la práctica totalidad del tronco y, en algunos casos, los glúteos.
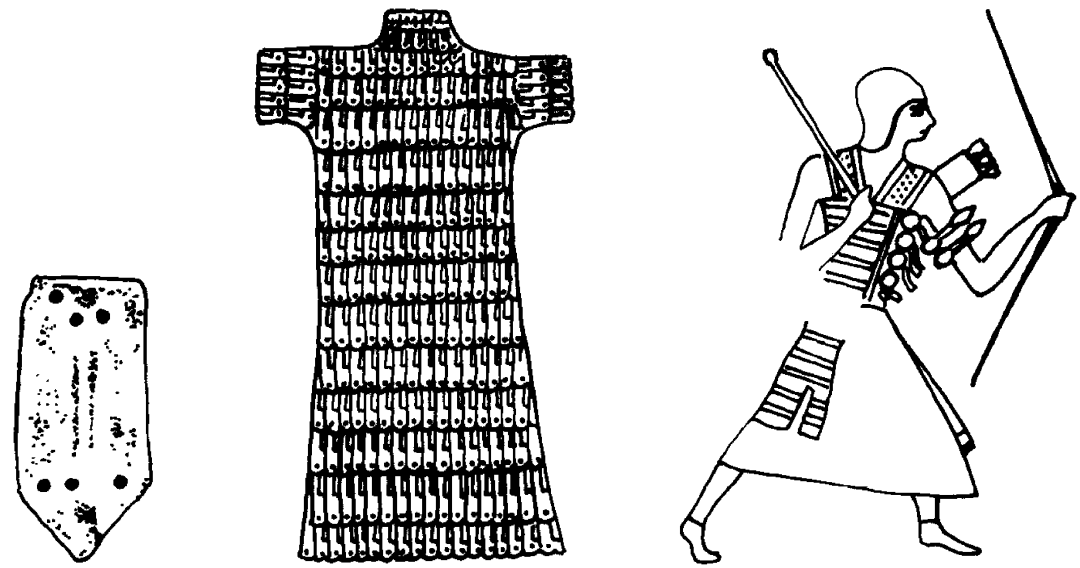

Figura 15. A: Placa de bronce, con agujeros para ser cosida a una pieza de tela, hallada en la antigua Pi-Ramsés. Dibujo a partir de foto en E. B. PusCH, 1993: 135, fig. 134. B: Cota, compuesta de pequeñas placas, pintada en la KV 11. Dibujo a partir de J. F. CHAMPOLLION, op. cit.: lám. 262. C: Soldado egipcio de la guardia de Ramsés Il protegido por casco y cota formada por grandes placas horizontales. Relive bélico del muro sur de la gran sala del templo mayor de Abu Simbel.

33 Para información sobre cotas en la antigüedad consultar en W. H. CATLING, Panzer. En Kriegswesen, vol I. Göttingen, 1977: 74-118. Sobre su introducción en Egipto leer, por ejemplo, en J. MARTíNEZ BABón, op. cit:: 26-27; Ibid.: Historia militar de Egipto durante la Dinastía XVIII. Barcelona, 2003: 187-189.

${ }^{34}$ Los distintos colores están en relación a los materiales diversos utilizados para la elaboración de esta cota: amarillo para oro, rojo para bronce y azul para fayenza. Esta conclusión, perteneciente a $H$. $L$. LORIMER, fue recogida por W. H. CATLING (op. cit:: 93). El uso de placas de materiales como hueso o cerámica para la fabricación de una cota de parada de esa época está documentado, desde el punto de vista arqueológico, en Pi-Ramsés (E. B. Pusch, op. cit:: 135). 
Unas anchas tiras colocadas sobre el hombro unían las partes posterior y anterior de la pieza, la cual quedaba fijada al cuerpo del guerrero mediante unos engarces laterales (fig.15-c). Protecciones similares, únicamente para el torso y parte del brazo, son portadas por soldados egipcios en la batalla naval del delta (fig.15-d). Probablemente estos corseletes estaban hechos de cuero, pues, al margen de la incomodidad para el movimiento, sería absurdo que los soldados de la flota se protegieran con una pesada pieza que podía provocar su muerte por ahogo si caían al agua ${ }^{35}$. El hecho de que la utilización egipcia de estos objetos defensivos coincidiera con la llegada de mercenarios foráneos que portaban prendas similares, permite la suposición de que se trata de armamento de origen extranjero ${ }^{36}$. Un tercer tipo de protección del tronco aparece también en la pared de la tumba de Ramsés III: se trata de dos piezas enteras unidas mediante engarces laterales; una cubría la totalidad del torso y la otra la espalda (fig. 15-e).
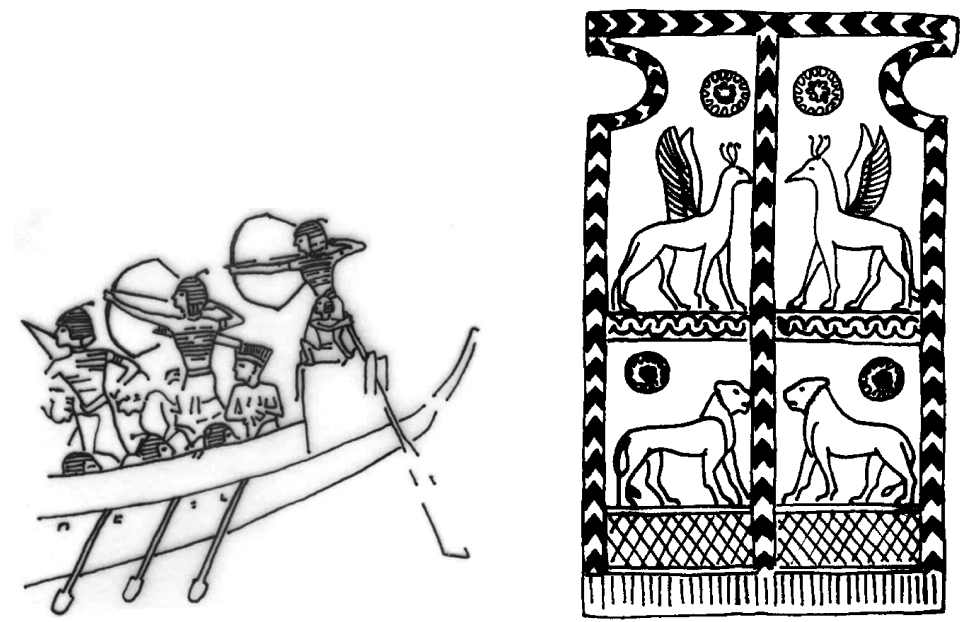

Figura 15. D: Soldados egipcios de la flota protegidos por cascos y cotas formadas por placas horizontales. Relieve bélico del templo funerario de Ramsés III en Medinet Habu.

E: Corselete formado por una única pieza, pintado en la KV 11. Dibujo a partir de J. F. CHAMPOLLION, op. cit.: lám. 264.

En lo que refiere a los cascos, debemos subrayar que eran portados por el mismo tipo de soldados poseedores de cota. Los relieves bélicos muestran protecciones de cabeza de distintas formas que cubrían parte de la frente y la totalidad del cráneo con nuca incluida (figs. 4-b, 13, 15-c y 15-d).

35 Probablemente las gruesas tiras de cuero estaban unidas mediante tiras de metal (W. H. CATLING, op. cit:: 103; R. DREWS, op. cit:: 175-176).

${ }^{36}$ En relieves del templo de Abu Simbel se pueden observar mercenarios schardana y soldados egipcios que portan este tipo de protección. Puesto que no se conocen antecedentes sobre esta clase de corselete en Egipto, podemos considerar que se trata de una innovación extranjera. 
A la citada lista esencial de armamento egipcio de la época en cuestión cabe añadir interesante novedad: las espadas largas. Es probable que estas armas, de origen centroeuropeo ${ }^{37}$, fueran introducidas en el país del Nilo por mercenarios schardana que entraron al servicio del faraón en tiempos de Ramsés II y cuyos descendientes combatirían bajo los estandartes egipcios, incluso contra guerreros de su misma procedencia ${ }^{38}$, durante el resto de la dinastía XIX y parte de la dinastía XX. Al margen de la información que ofrecen los relieves militares, se han encontrado diversas hojas de espada larga que ratifican su introducción durante esta época. Dos de las más representativas son (figs. 16-a/b):

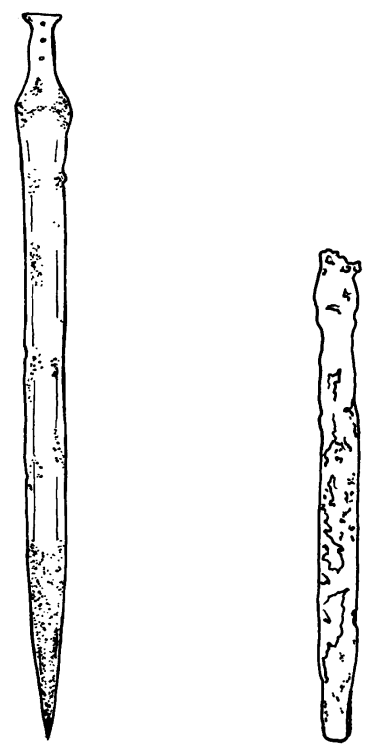

Figura 16. A: Fragmento de espada de bronce hallada en Zagazig. Museo Egipcio de Berlín, nr. 20447. B: Fragmento de espada de bronce con el nombre de Seti Il hallada en Tell Firaum. Museo Egipcio de Berlín, nr. 20305. Dibujos a partir de foto en W. WOLF, op. cit.: lám. 15.

a) Espada de bronce bien conservada hallada en Zagazig (Bubastis). Mide $71,5 \mathrm{~cm}$ de longitud. La hoja es de doble filo y posee cuatro acanaladuras. Indudablemente se trata de un arma de origen extranjero ${ }^{39}$.

\footnotetext{
${ }^{37}$ Hay evidencias de espadas largas en Egipto durante la Dinastía XVIII, pero se trataba de armas excepcionales (J. MARTíNEZ BABÓN, 2003: 181-182, 184-186). Sobre espadas largas egipcias de la época en cuestión: M. BURCHARDT, Zwei Bronzeschwerter aus Ägypten. ZÄS 50 (1912): 62; R. DrEWS, op. cit.: 199-201. Y sobre espadas largas y puñales de esta época en distintos ámbitos geográficos se puede consultar el capítulo de S. FoltinY, Schwert, Dolch und Messer. En Kriegswesen, vol. II. Göttingen, 1980: 231-274.

${ }_{38}$ Obviamente, si los schardana entraron al servicio de la Casa Real egipcia en tiempos de Ramsés II, algunas de sus unidades se enfrentaron contra los guerreros de su misma procedencia que formaban parte de la coalición de pueblos que atacó al país del Nilo, según informa la Gran Inscripción de Karnak.

39 M. BURCHARDT, op. cit:: 61.
} 
b) Hoja de bronce con alto grado de deterioro, de la cual se conservan $45 \mathrm{~cm}$, hallada en Tell Firaun (delta). Los cartuchos de Seti II grabados en una de las partes permiten datar con fiabilidad esta pieza ${ }^{40}$.

Otro objeto de este tipo y de especial interés se halló muy lejos de Egipto; se trata de una hoja que mide $74,4 \mathrm{~cm}$, posee acanaladuras y conserva una parte estrecha por la que se introdujo la empuñadura, hallada en Ras-Schambra (Ugarit). Su particularidad más destacable, desde el punto de vista histórico, es que porta los cartuchos del faraón Merenptah ${ }^{41}$. Este objeto demuestra, junto a otras evidencias, el grado de colaboración alcanzado entre la corte egipcia y sus antiguos enemigos sirios en tiempos del citado rey.

Como ocurrió con otras armas incorporadas a la dinámica militar egipcia, la llegada de espadas largas al país del Nilo no supuso ningún cambio sustancial en el armamento: el hacha seguiría siendo el arma más común para los soldados del faraón en la lucha cuerpo a cuerpo.

\section{ELABORACIÓN, ALMACENAJE Y REPARTO DE ARMAMENTO}

Si bien la elaboración de armamento está perfectamente documentada, como ya ha sido indicado, en la antigua Pi-Ramsés, otras pruebas ayudan a perfilar el trabajo que efectuaban los artesanos en armerías y talleres. En Sakkara se hallaron tumbas de algunos funcionarios que se dedicaban a la inspección metalúrgica en los arsenales menfitas de finales de la dinastía XVIII y comienzos de la XIX ${ }^{42}$. Inscripciones y relieves conservados en sus paredes aportan información sobre el tipo de armas que se fabricaban en Egipto durante esa época. Un relieve de la tumba de Ipuya, jefe de taller y superior de orfebres del Señor de las Dos Tierras, muestra, entre trabajos de cariz civil como la elaboración de estatuas, a unos artesanos puliendo la rueda de un carro (fig. 17). Y deteriorados fragmentos de re-

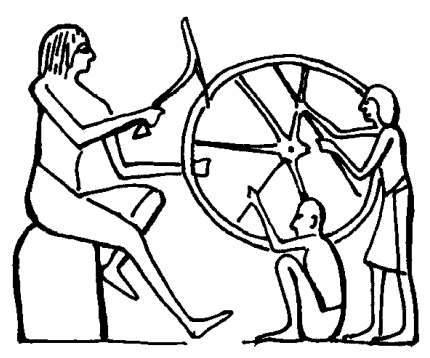

Figura 17. Artesano menfita puliendo la rueda de un carro. Tumba de Ipuia en Sakkara. Dibujo a partir de S. SAUNERON, op. cit.: 10, fig. 1.

40 Ibid.: 61-62.

41 C. F. A. Schaeffer, A Bronze Sword from Ugarit with Cartouche of Mineptah (Ras Shambra, Syria). Antiquity 29 (1955): 226-229. En opinión de este investigador la espada fue elaborada en armerías del Próximo Oriente.

${ }^{4}$ S. SAUNERON, La manufacture d'armes de Memphis. BIFAO 54 (1954): 7-12. 
lieves de la tumba de Kyry, jefe de taller del Señor de las Dos Tierras, Superior de fabricantes de carros y Jefe del taller del arsenal, permiten observar la elaboración de flechas y el traslado de carros desmontados, espadas curvas y cascos a los almacenes.

La información sobre armerías en Pi-Ramsés y Menfis, añadida a la que poseemos sobre talleres tebanos de la dinastía XVIII, permite afirmar que había lugares dedicados a la producción de armas en las ciudades que poseían acuartelamientos donde habitaban los soldados pertenecientes a las divisiones de combate. Dicho de otra manera, probablemente la alta oficialidad de una división tenía también algún tipo de competencia sobre la fabricación de objetos para la guerra. Obviamente, los tributos, como los arcos simples y escudos forrados de pieles procedentes de Kusch que aparecen en las paredes del templo de Ramsés II en Beit el-Walli (fig.18), y el botín de guerra, como la lista de armas incautadas al enemigo que contiene la Gran Inscripción de Karnak escrita en tiempos de Merenptah ${ }^{43}$, contribuyeron a engrosar el armamento de los ejércitos del faraón.

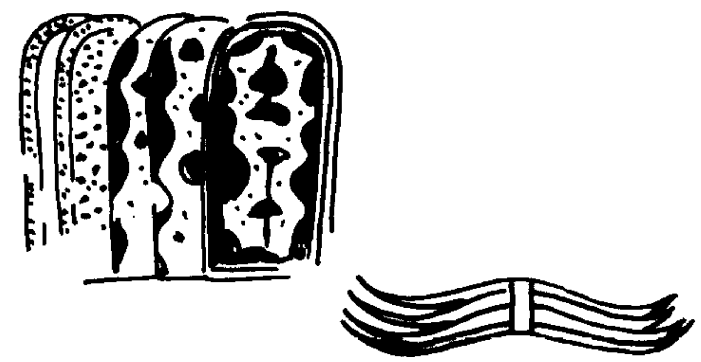

Figura 18. Escudos y arcos como tributos nubios entregados a Ramsés II. Muro sur del patio del templo de Beit el-Walli.

Las armas que no eran necesarias para el servicio de las unidades en activo eran trasladadas y guardadas en grandes almacenes. Y allí permanecían hasta que las variables geopolíticas obligaban al faraón a movilizar grandes cantidades de soldados. Las paredes de la citada tumba de Ramsés III muestran, como se ha podido constatar, un almacen que poseía buena parte de la panoplia egipcia de aquella época: espadas rectas, espadas curvas, venablos, arcos, bastones y todo tipo de protecciones corporales. También en los mencionados relieves de la tumba de Kyry era posible observar abundantes objetos bélicos colocados en almacenes $^{44}$. Entre los mismos, se pueden destacar: carros, cascos y venablos.

Ante una situación de alarma eran llamados a filas todos los reservistas y se procedía al reparto del armamento almacenado. Un relieve del templo funerario de Ramsés III en Medinet Habu recoge el momento de entrega de armas a los sol-

43 En la lista de botín se recogen los términos: Espadas de los mescheuesch: 9111.

44 S. SAUNERON, op. cit: 11. 
dados que deben participar en una operación de defensa del territorio frente a invasores hostiles. La escena presenta al faraón presidiendo la entrega de cascos, lanzas, arcos compuestos, carcajs y espadas curvas (fig.19).

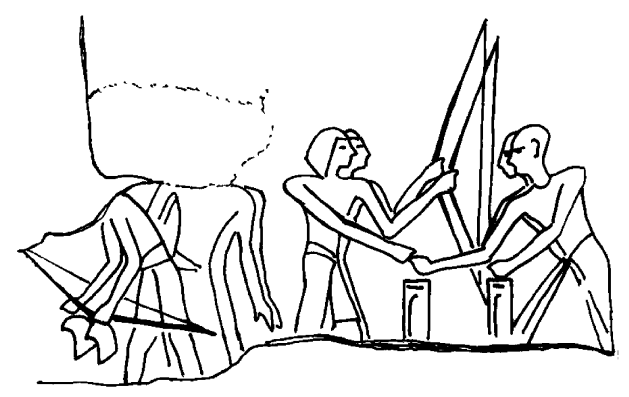

Figura 19. Entrega de armas a los soldados como preámbulo de una campaña militar. Relieve bélico del templo funerario de Ramsés III en Medinet Habu.

\section{CONCLUSIONES}

Las estructuras militares de las dinastías XIX y XX poseían el armamento más moderno que en aquella época había en el Próximo Oriente asiático. Sin embargo, no renunciaron a armas tradicionales, como el hacha y el arco simple, que eran contundentes en el campo de batalla, fáciles de elaborar en comparación con otros objetos bélicos y más baratos. Cabe tener en cuenta que la carencia de grandes bosques en Egipto jamás permitió un amplio desarrollo de la industria metalúrgica. Evidentemente, sin ingentes cantidades de madera no se podía trabajar en grandes hornos de fundición. De esta manera, el país del Nilo debía importar materiales de elaboración y armas desde sus territorios asiáticos, capturarlas como botín o fabricar masivamente aquellos objetos bélicos que resultaran más económicos.

El ejército de las dinastías XIX y XX combatió básicamente con el mismo tipo de armas que el de finales de la dinastía XVIII, aunque hubo, a lo largo del tiempo, algunas innovaciones técnicas, ampliaciones en el uso de determinados objetos y la incorporación de un arma nueva:

- En el marco de las mejoras técnicas se puede destacar el aumento de la capacidad de combate de los carros, el cambio de la forma de las puntas de flecha con el fin de aumentar su capacidad de destrucción y la introducción de un nuevo tipo de protección corporal más ligero.

- Sobre la extensión del uso de algunas armas cabe subrayar el arco compuesto y, en cuanto a defensa, las cotas o los corseletes, en sus diversas modalidades, y los cascos. No hay que olvidar, sin embargo, que en una primera fase las protecciones corporales fueron destinadas, básicamente, a las unidades de la guardia real y de carros. 
- Las largas espadas de origen centroeuropeo constituyen la novedad armamentística más destacada de todo este período. Estas armas, portadas por mercenarios y algunos egipcios, podían ser más efectivas que las hachas y las espadas curvas.

Desde el punto de vista histórico se puede afirmar que las tropas de Seti I y Ramsés II que participaron en numerosas campañas contra objetivos asiáticos estaban perfectamente armadas y pertrechadas. En los talleres y armerías situados en las ciudades que poseían división de combate se fabricaban objetos bélicos que requerían una utilización limitada de la metalurgia. El resto del material de guerra procedía de dominios egipcios situados en tierras extranjeras o de las armas que portaban los mercenarios que a lo largo de esta época se fueron incorporando al ejército del faraón. Asimismo, la paz firmada con el antiguo enemigo hitita en el año 21 de Ramsés II permitió la llegada de artesanos anatólicos que contribuyeron a mejorar la calidad técnica de algunos objetos bélicos.

La situación comenzó a variar ante los ataques externos acaecidos en tiempos de Merenptah y las crisis internas que se produjeron en la última fase de la dinastía XIX: Ios incipientes signos de debilidad en un marco geopolítico internacional inestable tendrían también sus repercusiones en el ejército y su armamento. En pocas décadas el país del Nilo pasó de ser una potencia imperialista a un territorio que hubo de movilizar todos los recursos disponibles para rechazar agresiones de libios y Pueblos del Mar. Asimismo, la figura del faraón como primer guerrero del Imperio sufriría un gran desgaste debido a las pugnas desatadas en la Casa Real que culminarían con un cambio dinástico. Semejante deterioro contribuyó a debilitar al ejército, provocó pérdidas territoriales y, por tanto, socavó la capacidad de obtener armamento de muchos centros asiáticos.

Durante la primera fase de la dinastía XX tendrían lugar las últimas grandes batallas del ejército neoimperial contra invasores extranjeros. $Y$ un aspecto histórico sumamente interesante radica en la comparación de los relieves militares de Ramsés III, el gran guerrero de esta dinastía, con los de Ramsés II. Partiendo del constatable hecho de la acentuada similitud en muchos aspectos, encontramos, desde el punto de vista armamentístico, un elemento distinto: en las tropas de Ramsés III que combatieron contra libios y Pueblos del Mar aparecen unidades de soldados que portan un bastón de combate o una maza, armas escasas en los numerosos relieves de Ramsés II. El bastón también forma parte de la panoplia egipcia en la pintura de la tumba de Ramsés III. Y en tiempos de este último se observa también la presencia de honderos dentro de las fuerzas armadas. Esta sutil diferencia en los relieves tal vez nos esté dando una información importante: algunas unidades de soldados portaban armas que podemos considerar excesivamente baratas para un ejército que en épocas anteriores estaba perfectamente armado. $Y$ ello se puede deber a dos razones:

- La pérdida de influencia sobre ciudades asiáticas con tradición metalúrgica había obligado a utilizar armas de fabricación simple y escaso coste. 
- La movilización general de soldados, reservistas y milicianos provocó una falta de armas que se solventaría con la elaboración rápida de objetos bélicos simples.

Evidentemente, no puede descartarse una incidencia de ambos factores.

Poco se sabe sobre el armamento de la última fase de la dinastía XX. Sin embargo, las pérdidas de los últimos territorios asiáticos, el desgobierno y los conatos de guerra civil que marcaron el fin del Imperio Nuevo permiten suponer que disminuyó la calidad de los objetos bélicos. 